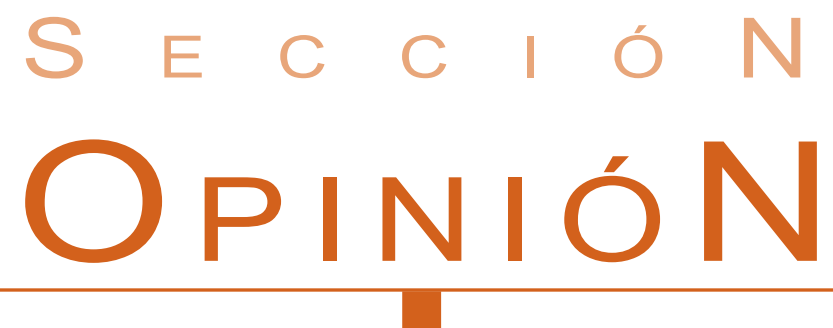




\begin{tabular}{|c|c|}
\hline \multicolumn{2}{|c|}{$\begin{array}{l}\text { FACULTAD DE INGENIERÍA } \\
\text { UNIVERSIDAD DE LOS ANDES }\end{array}$} \\
\hline \multirow[t]{6}{*}{ Programas de Pregrado: } & Ingeniería Civil y Ambiental \\
\hline & Ingeniería Eléctrica y Electrónica \\
\hline & Ingeniería Industrial \\
\hline & Ingeniería Mecánica \\
\hline & Ingeniería Química \\
\hline & Ingeniería de Sistemas y Computación \\
\hline Programas de Magíster en Ingenierías: & $\begin{array}{l}\text { Civil, Eléctrica y Electrónica, Industrial, } \\
\text { Mecánica, Sistemas y Computación. }\end{array}$ \\
\hline \multicolumn{2}{|l|}{ Programa de Doctorado en Ingeniería } \\
\hline \multicolumn{2}{|c|}{$\begin{array}{c}\text { Decanatura de Ingeniería } 33243 \text { 27/28/29/31 Fax } 3324330 \\
\text { e-mail: citec@uniandes.edu.co }\end{array}$} \\
\hline \multicolumn{2}{|c|}{ Santafé de Bogotá } \\
\hline
\end{tabular}




\title{
La Etica y la Calidad en la Ingeniería Colombiana
}

\author{
Heberto Jiménez Muñoz ${ }^{1}$
}

\section{Resumen}

La profunda crisis ética, moral y de valores que afronta el país fruto de un proceso de descomposición social, económica y política que viene afectando en forma creciente la vida del pais, ha afectado todos los campos de la actividad productiva nacional incluyendo en forma manifiesta el de la contratación y ejecución de las obras, instalaciones y servicios requeridos para el desarrollo de la infraestructura económica y social.

Si bien el conjunto de factores que ha llevado a la situación francamente patológica descrita por el análisis de múltiples casos de corrupción en la contratación pública conocidos por la opinión nacional es muy amplio y complejo, se pueden identificar en principio, factores claves que comenzando por el de la formación profesional, deben modificarse y corregirse por acción de los agentes involucrados, a fin de superar esta crisis en la ejecución de las tareas del desarrollo nacional que corresponde a nuestro gremio de la ingeniería, así:

\section{La NORMATIVIDAd}

El estatuto de contratación oficial, promulgado mediante la Ley 80 de 1993, requiere un replanteamiento básico a fin de corregir los efectos severamente adversos que ha determinado en los campos de la contratación de construcción de obras y de prestación de servicios de consultoría en todas sus formas.

La normatividad vigente deberá, entre otros y múltiples aspectos señalados por los gremios (AICO, ACIC), corregir la aberrante condición actual de el registro de proponentes que consagra la capacidad de contratación de los posibles contratistas, con base en los datos estadísticos del pasado es decir que condiciona la capacidad de contratación de la ingeniería, no a su propio potencial, sino a la pobre cuantía de inversión pública del Estado en los lustros o años precedentes.

\section{La Contratación Oficial}

Conforme al régimen vigente, la mayoría de los Institutos descentralizados y las Empresas comerciales e in- dustriales del Estado contratan bajo normas de derecho privado y cada uno de ellos ha organizado su propio registro de proponentes, en forma que los principios de transparencia y economía pueden ser fácilmente vulnerados.

En estos organismos bajo régimen excepcional de contratación, el nivel ético y de calidad en la contratación es función de las calidades morales de los administradores gerenciales y de la bondad de los métodos de contratación y selección de contratistas, que al alcanzar un alto nivel, deben conducir a selección de contratistas de probadas condiciones éticas y de calidad.

En caso contrario, se evidencian inadecuada selección de contratistas, corrupción en la contratación y pobres condiciones de calidad, con nítida responsabilidad de las Firmas ejecutoras y/o interventoras y culpabilidad correlativa de los Gerentes contratantes por acción, omisión, incapacidad o inexperiencia en la contratación pública.

La contratación bajo las normas de la vigente Ley 80/93, si bien ha conducido a una contratación más expedita y con los aspectos formales de una pretendida "transparencia", ha producido los siguientes efectos adversos

1 Presidente de la Sociedad Colombiana de Ingenieros 
al interés nacional, efectos que deberán corregirse mediante las pertinentes modificaciones a la Ley:

- Propicia la contratación de construcción a precios no costeables, con frecuentes situaciones de incumplimiento y crisis de obras públicas.

- Se hace posible la intermediación dolosa en contratos de construcción y consultoría.

- Desde su promulgación condujo a contratación de diseños, asesorías e interventorías de firmas o profesionales frecuentemente sin calificación, experiencia y competencia adecuadas, al otorgar casi siempre un alto peso al menor precio de los proponentes o a un precio función del presupuesto oficial y la media geométrica de las ofertas de los proponentes, con resultados adversos que hoy enfrentan entidades públicas.

- Ante una limitada demanda de trabajo y una artificialmente elevada oferta de Firmas, en razón de la condición de pública licitación para contratación, el Estado colombiano (organismos oficiales del poder central y entes territoriales) están contratando a precios no costeables a mas de que ante contratos de adhesión a precio fijo, se están imponiendo plazos precarios y alcances exorbitantes con responsabilidades de igual carácter, no sustentables en forma efectiva por los contratistas. Las consecuencias adversas para los proyectos y las inversiones ya se están evidenciando.

- Coloca a las Firmas nacionales de en inferioridad de condiciones frente a las firmas foráneas para las cuales establece una condición de reciprocidad que se ha convertido en una exigencia teórica.

- Ha substituido la relación de conocimiento y confianza entre las partes contratantes de la consultoría, por una relación comercial entre contratante y postor, que está conduciendo y conducirá inexorablemente a más corrupción y a una mayor crisis en la calidad de las obras y de los procesos de consultoría.

- Establece un régimen de responsabilidad exorbitante para el representante legal contratante y discriminatorio contra los contratistas de obras públicas, con penas y condiciones de prescripción que no se aplican ni al terrorismo, condiciones que han llevado a Términos de Referencia excluyentes y proliferación de conflictos jurídicos.

\section{La Ejecución de Contratos de CONSTRUCCIÓN}

Las Firmas nacionales de construcción deberán garantizar condiciones mas firmes de disponibilidad de equipos y establecer sistemas de control interno mas eficaces en cuanto a programación, ejecución y control de calidad de las obras, en respuesta a una realidad precaria que evidencian todas las encuestas y pronunciamientos de la opinión pública.

La SCI, con ACIC, deberían propiciar un sistema de certificación para firmas de probada excelencia de calidad en la ejecución de obras.

\section{LA EJECUCIÓN DE ESTUDIOS, DISEÑOS E INTERVENTORÍAS}

La Firmas de consultoría comprometidas con normas éticas y de control de calidad deberían certificarse por gremios acreditados y de probada seriedad y responsabilidad técnica, operacional y ética, tales como AICO.

Estos gremios, a manera de clubes de calidad y ética total, deberán marcar la diferencia entre Firmas consultoras con prácticas profesionales aceptables a nivel nacional e internacional, en contraposición al nivel de otras que muestran, según las mismas encuestas, irresponsabilidad, falta de autoridad y complicidad con obras de mala ejecución y calidad.

\section{EL EJERCICIO PROFESIONAL Y LOS CÓDIGOS DE ÉTICA}

Debería actualizarse y ratificarse el código de Ética Profesional de la Ingeniería, promulgado por Resolución Ministerial de la década de los años 80 , estableciendo como condición para pertenecer a la SCI y a los Gremios de la Construcción y la Consultoría, el juramento de cumplirlo.

Así mismo deberá estimularse la función de vigilancia de la Ética Profesional que por normas legales ejerce el Consejo Profesional de Ingeniería y sus Profesiones Auxiliares.

ÉTICA PRIVADA Y ÉTICA PÚBLICA 
La Ética Profesional como expresión de la Ética Privada es fundamental en la construcción de la Cultura de Confianza que constituye la base fundamental de la viabilidad y competitividad económica de una sociedad y de un país frente al mundo.

Los análisis de la Comisión de Economía y Planeación de la SCI efectuados a través de publicaciones en secuencia desde 1990 muestran que la Ética Pública en Colombia ha sufrido un proceso de deterioro que la coloca en los niveles más bajos del continente.

Los recientes pronunciamientos de la Contraloría General de República, de la Procuraduría y de la Fiscalía General de la Nación confirman tales planteamientos.

En tal condición reiteramos consideraciones de nuestro documento: "Los Factores Estratégicos del Crecimiento Integrado Nacional - Julio de 1998" así:

Stephen Covey, fundador y presidente del afamado Centro Covey para el liderazgo (CLC) en forma que resulta plenamente significativa para nuestro país anota:

"En la economía global no se puede competir, no se puede ser viable, si no se tiene alta calidad a bajo costo, y no se puede conseguir alta calidad y bajos costos sin una cultura de alta confianza".

"No se puede conseguir una cultura de "alta confianza", .....si no se esta centrado en los principios. La confianza proviene de los principios".

"Los principios a los que me refiero son los principios básicos universales que corresponden a todas las relaciones humanas y organizaciones, por ejemplo la justicia, el juego limpio, la honestidad, la integridad y la confianza".

"En el movimiento de calidad del pasado, el énfasis estaba en las tecnologías y en las estructuras, los sistemas y los procesos y no en la construcción de culturas de "alta confianza"

"El paradigma fundamental de la administración y el liderazgo debe cambiar"

\section{DEMOCRACIA Y CORRUPCION}

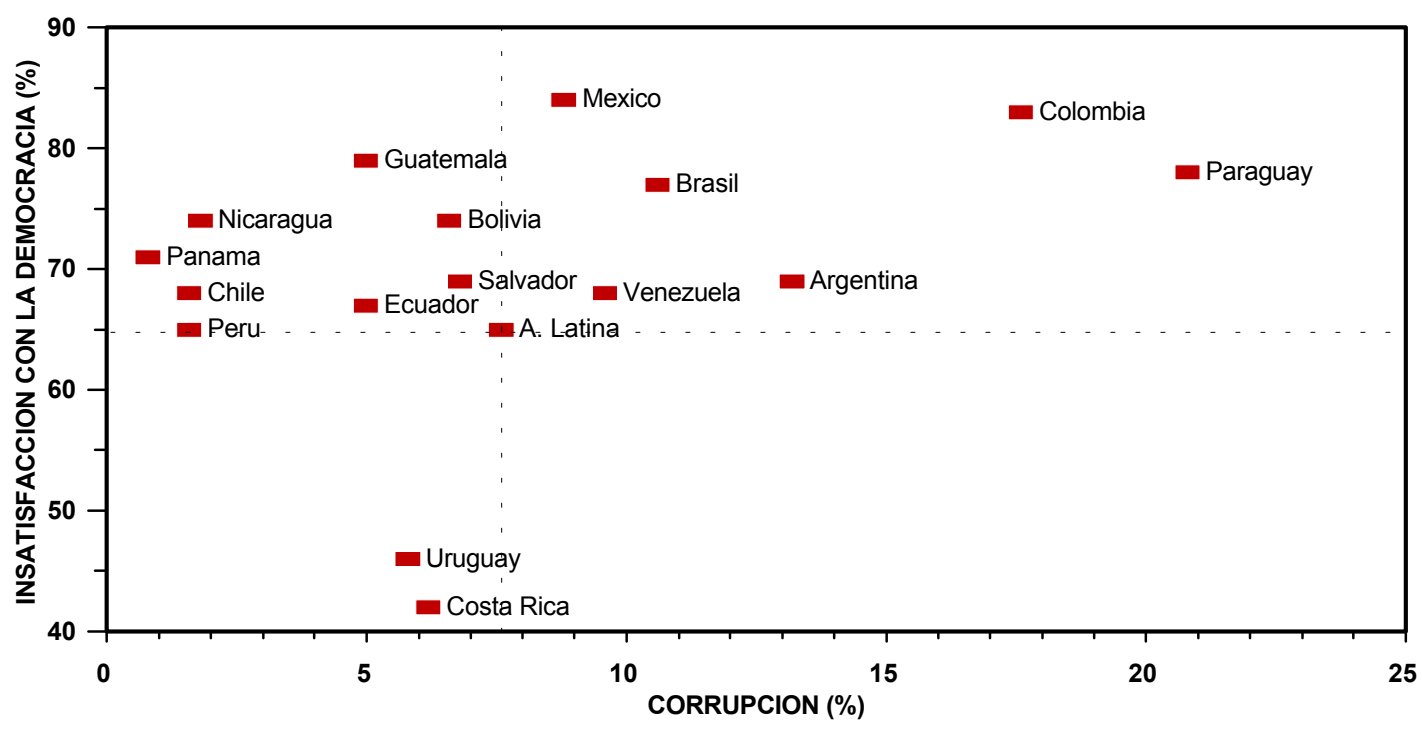

FUENTE: Encuesta Latinobarómetro (17 países). Feb 1998 